\title{
Nothing to be ashamed of: sex robots for older adults with disabilities
}

\author{
Nancy S Jecker [1]
}

Department of Bioethics and Humanities, University of Washington, School of Medicine, Seattle, Washington, USA

\section{Correspondence to} Dr Nancy S Jecker, Department of Bioethics \& Humanities, University of Washington, Seattle, Washington, USA nsjecker@uw.edu

Received 29 June 2020 Accepted 25 August 2020 Published Online First 16 November 2020

\section{Linked}

- http://dx.doi.org/10.1136/ medethics-2020-106927

- http://dx.doi.org/10.1136/ medethics-2020-106928

- http://dx.doi.org/10.1136/ medethics-2020-106932

- http://dx.doi.org/10.1136/ medethics-2020-106957

\section{Check for updates}

(C) Author(s) (or their employer(s)) 2021. No commercial re-use. See rights and permissions. Published by BMJ.

To cite: Jecker NS J Med Ethics 2021;47:26-32

\section{ABSTRACT}

This paper spotlights ways in which sexual capacities relate to central human capabilities, such as the ability to generate a personally meaningful story of one's life; be physically, mentally and emotionally healthy; experience bodily integrity; affiliate and bond with others; feel and express a range of human emotions; and choose a plan of life. It sets forth a dignity-based argument for affording older people access to sex robots as part of reasonable efforts to support their central human capabilities at a floor level. The argument develops stepwise: (1) first, I dispel ageism and negative stereotypes about later-life sexuality, showing their deep historical roots in medicine and science; (2) second, I set forth a positive argument, grounded in capability accounts of justice, for deploying sex robots for older people with disabilities; (3) finally, after responding to objections, I conclude that sex robots are a reasonable way to support later-life sexuality for persons with disabilities. While often depicted as a product for younger, able-bodied people, this paper is a bid for reimagining sex robots as a product for older, disabled people.

\section{INTRODUCTION}

The sexual lives of older adults is a neglected topic in medical research and practice. It was not until 2007 that the first national US study of sexuality among home-dwelling older adults was published, ${ }^{1}$ extending our understanding of later-life sexuality beyond observations of institutionalised persons with dementia. ${ }^{2}$ Contrary to common stereotypes of older adults as asexual, the landmark study showed that more than half $(53 \%)$ of older adults aged 65-74 years were sexually active, and more than a quarter $(26 \%)$ of older adults aged $75-85$ years were. ${ }^{3}$ One explanation for the near absence of inquiry prior to 2007 is ageism. The WHO defines 'ageism' as 'stereotyping, prejudice and discrimination towards people on the basis of age', which 'cuts across the life-course and stems from the perception that a person might be too old or too young to be or to do something' (Officer, p299). ${ }^{4}$ Not only in research but also in everyday life, ageism infiltrates attitudes about sexuality: attempts by older persons to express sexuality and intimacy are often ridiculed, ${ }^{5}$ while stereotypes depict older adults as asexual, ${ }^{6}$ prudish and beyond sex. ${ }^{7}$ Within healthcare, providers routinely avoid the topic of sexual health with patients over 65 years, despite a much higher frequency of health-related sexual concerns in this age group. ${ }^{89}$

This paper highlights the ethical importance of combatting ageism about later-life sexuality by pointing to ways in which it relates to human dignity and to central human capabilities, such as the ability to generate a personally meaningful story or narrative of one's life; be physically, mentally and emotionally healthy; experience bodily integrity; affiliate and bond with others; feel and express a range of human emotions; and choose a plan of life. Focusing on older people with disabilities, the paper sets forth an ethical argument for affording access to sex robots as part of reasonable efforts to support central human capabilities at a floor level. The argument has some force with respect to all older people, since age-related changes affecting sexual functioning impact all people as they grow old. It also carries implications for younger people who lack access to sex partners; for example, in China, gender imbalance resulting from Mao's one-child policy has made it difficult for young men who prefer sex with women to find a partner. Yet, I bracket discussion of these topics for another day and focus on older people with disabilities, including both those with and those without human partners. Throughout the paper, the term, 'sex robots' is used to refer to 'life-size machine entities with human-like appearance, movement, and behaviour, designed to interact with people in erotic and romantic ways... with capabilities ranging from simple verbal responses, to physical movements, to more advanced artificial intelligence' (Gersen, p1794-95). ${ }^{10}$ Unlike other objects used to enhance sexual activity, sex robots simulate being with another human being and involve forming a human-robot relationship.

The argument for affording access to sex robots for older people with disabilities develops stepwise: (1) I begin by dispelling ageism and negative stereotypes about later-life sexuality, showing their deep historical roots in medicine and science; (2) next, the paper sets forth a positive argument, grounded in capability accounts of justice, for making available sex robots for older people with disabilities; the argument links such support to respect for human dignity; (3) finally, after responding to objections, I conclude that sex robots are a critically important tool to support sexuality for older persons with disabilities. While often depicted as a product designed for younger, able-bodied people, this paper is a bid for reimagining sex robots as a product to support older adults with disabilities.

\section{AGEISM ABOUT LATER-LIFE SEXUALITY}

All older adults undergo physical changes that affect sexual enjoyment. For older women, this includes shortening and narrowing of the vagina, thinning of the vaginal walls, and reduced lubrication; for older men, it includes taking longer to have an 
erection, not having an erection as firm or long as in the past, or longer duration between erections. ${ }^{11}$ Chronic conditions such as arthritis, chronic pain, dementia, diabetes, heart disease, incontinence and stroke do not affect every older person, yet they occur with far higher frequency during later life and can interfere with sexual functioning when they do. While age-related changes and chronic disease can be disruptive to sexual activity, they do not eliminate older adults' sexual feelings or preclude engaging in sexual activities with assistance. At each stage of life, people adapt their sexual expression and activities to fit their circumstances and capabilities. Thus, 'the careful lovemaking of a 70-something couple may bear little resemblance to the lusty pairings of 20-year-olds ... greater experience, fewer inhibitions, and a deeper understanding of your preferences and those of your partner can more than compensate for the (physiological) consequences of ageing, such as slower arousal, softer erections, reduced vaginal lubrication and less intense orgasms' (Shifren, p5). ${ }^{12}$

For older adults with chronic disease or disability, it can be much harder or impossible to satisfy sexual interests without assistance. Since the number of chronic conditions rises sharply from late middle age onward, this has important implications for older adults. By the time people reach age 65 years, over half experience two or more chronic conditions; by age 85 years, virtually all older people (95\%) experience two or more chronic conditions. $^{13}$

Diminished sexual capacity encompasses far more than diminished ability to accomplish the act of sexual intercourse itself. According to the WHO's working definition, sexuality encompasses 'sex, gender identities and roles, orientation, eroticism, pleasure, intimacy and reproduction' (World Health Organization, p5). ${ }^{14}$ So understood, sexuality relates to broader attempts to find meaning, maintain health, have bodily integrity, express emotions and affiliate deeply. While not all human beings identify themselves as sexual, ${ }^{15}$ most regard sexuality as an essential component of their identity. For them, sexual contact with others is not only a source of pleasure but also serves as a source of pride and shame, a vehicle for expressing who they are as persons.

\section{Countering ageism}

More than physical limitations stand in the way of later-life sexuality. People in many societies cherish youthful beauty and react with distaste to the bodies of older adults, comparing them unfavourably to a former youthful individual. The roots of negative responses to aged bodies run deep. During the early 20th century, medicine labelled attraction to older individuals pathological. Krafft-Ebbing coined the term gerontophilia in 1901 to refer to the condition of being primarily sexually attracted to older individuals. ${ }^{16}$ The Oxford English Dictionary defines 'gerontophilia' as 'loving or favouring old people, especially old men; desiring sexual relations with old people'. ${ }^{17}$ According to Krafft-Ebing, there exists an age range where sexual arousal and behaviour is 'normal' and physiologically based, with childhood and old age both falling outside the normal range. ${ }^{18}$ Later in the 20th century, early psychoanalysis explained sexual attraction to older people as a disruption produced by a 'grandfather complex', which occurs when a grandparent replaces the Oedipal parent, who is the normal object of attraction. ${ }^{19}$ In contemporary medicine, gerontophilia has often been regarded as a type of paraphilia, although it has not explicitly mentioned in the American Psychiatry Association's Diagnostic and Statistical Manual of Mental Disorders (DSM) or the WHO's International Classification of Diseases. 'Paraphilia' indicates a condition characterised by 'experiencing, over a period of at least 6 months, recurrent, intense sexually arousing fantasies, sexual urges, or behaviours generally involving nonhuman objects or nonconsenting partners'. ${ }^{20}$ Contemporary researchers, such as Janssen, argue that gerontophilia belongs in the Diagnostic and Statistical Manual of Mental Disorders, Fifth Edition (DSM-5), category of 'paraphilia, other specified' or 'unspecified paraphilic disorder'.21 Giving a scientific sheen to the proposed classification of gerontophilia as a paraphilia, contemporary scientists have argued that, like paedophilia, gerontophilia is non-procreative and serves no evolutionary purpose. ${ }^{22}$ Reflecting the early work of Krafft-Ebing, contemporary researchers continue to characterise normal and abnormal age orientations. Bering, for example, describes six erotic age orientations and regards both ends of the age spectrum, represented as paedophilia and gerontophilia, as deviant. Money classifies three age orientations as paraphilic: gerontophilia, ephebophilia and paedophilia. ${ }^{23} \mathrm{He}$ defines gerontophilia as applying exclusively to cases involving people of different ages; thus, in gerontophilia, 'a young adult is inwardly compelled always to seek a partner old enough to be either a parent or, in some instances, a grandparent' (Money, p173). ${ }^{23}$ Others recognise sexual attraction between older people as gerontophilia. $^{24}$

\section{ETHICAL ARGUMENT FOR SEX ROBOTS FOR OLDER PEOPLE WITH DISABILITIES}

Given ageist attitudes toward old age sexuality, it should come as no surprise that sex robots are generally not pitched to older people with disabilities. Instead, the current sex robot industry is focused on young, able-bodied, male clientele. Typical is the New Jersey-based company, TrueCompanion, which markets Roxxxy, a life size sex robot pictured as a large-breasted young woman with five preprogrammed girlfriend personalitiesFrigid Farrah, Wild Wendy, S\&M Susan, Young Yoko and Mature Martha. ${ }^{25}$ Designing and marketing sex robots to older disabled people would represent a sea change from current practice. What reason could there be for pressing for such a change? In this section, I argue that a society which supports human dignity must take seriously the claims of those who lose the ability to be sexual and must make reasonable efforts to help.

Much of the ethics debate about sex robots reflects a utilitarian bent, focusing on benefits versus harms sex robots yield. Proponents, such as McArthur, argue that 'Sexbots are coming, and this will be, on net, a good thing. People will enjoy having them, and they will be happier as a result' (McArthur, p43). ${ }^{26}$ Levy maintains that ' $[\mathrm{t}]$ he social and psychological benefits will be enormous. Almost everyone wants someone to love, but many people have no one. If this natural human desire can be satisfied for everyone... surely the world will be a much happier place' (Levy, p303). ${ }^{27}$ Drawing on transhumanist philosophy, Hauskeller holds that the transhumanist agenda rests firmly on hedonism: the goal is always 'to get the maximum amount of pleasure out of everything we do' (Hauskeller, p214). ${ }^{28}$ The great advantage of sex robots is that they are reliable founts of pleasure, in contrast to human partners, which are unreliable and thereby inferior: 'the problem with entering into relationships with other people is that, although they certainly can be a source of pleasure, more often than not they stand in the way of it. Moreover, even when they give us pleasure and happiness... this pleasure can always be taken away ....' (Hauskeller, p196) ${ }^{29}$

In contrast to utilitarian arguments, a capability approach evaluates sex robots in terms of what they enable people to do and be. These doings and beings are regarded as ultimate ends, 
rather than mere means to some other valuable good, such as pleasure or well-being. In the analysis that follows, I do not defend the capabilities approach itself, but instead apply it to the case of sex robots to show another way of framing an argument for sex robots, a way that provides much surer footing for the claims of older people with disabilities.

As the discussion of ageism in medicine and science makes evident, older people's sexual functioning is vulnerable, not just to physical changes related to ageing, disease and disability but also to being a target of social stigma and scorn. Yet just as society has the power to insult people's dignity by shaming and stigmatising their sexual desires and behaviour, it has the power to support dignity and serve as a bulwark against shame. Drawing on this insight, a capability argument for sex robots sets out the central kinds of things that humans can do and be and argues that supporting dignity requires supporting these central doings and beings at a minimum threshold.

A capability argument begins with a list of central human capabilities, such as the following list, adapted from Nussbaum, ${ }^{30}$ and defended at greater length elsewhere: ${ }^{31}$

\section{Central human capabilities}

1. Life: having an unfinished narrative.

2. Health: being able to have all or a cluster of the central capabilities at a threshold level.

3. Bodily integrity: being able to use one's body to realise one's goals.

4. Senses, imagination and thought: being able to imagine, think and use the senses.

5. Emotions: being able to feel and express a range of human emotions.

6. Practical reason: being able to reflect on and choose a plan of life.

7. Affiliation: being able to live for and in relation to others.

8. Nature: being able to live in relation to nature and other species.

9. Play: being able to laugh, play and recreate.

10. Environment: being able to regulate the immediate physical environment.

If we accept that this is at least a plausible list, the next step will be to show the interplay of human sexuality with these central human capabilities. This part of the argument comes into sharper focus by enumerating ways in which being sexual is integral to six capabilities: the capability to have a life narrative; be emotionally, mentally and physically healthy; experience bodily integrity; feel and express a range of human emotions; reflect on and choose a plan of life; and affiliate deeply with others. If the ability to be sexual is linked to these capabilities, this forms the basis for the claim that societies should support sexual capabilities at a minimal level because doing so is part and parcel of supporting the six central human capabilities. When sexual capabilities dip below a minimal level, as they do for many older adults with disabilities, a capability view requires reasonable steps to shore up sexual capabilities. The argument can be summarised as follows.

\section{Dignity-based argument for sex robots}

1. Older adults frequently suffer disabilities that impair sexual functioning.

2. The ability to function sexually is linked to central human capabilities, including the ability to generate a personally meaningful life narrative; be physically, mentally and emotionally healthy; experience bodily integrity; feel and express a range of human emotions; affiliate deeply with others; and reflect on and choose a plan of life.

3. Society should take reasonable steps to support these human capabilities at a minimal threshold as part of a broader duty to respect human dignity.

4. Providing access to sex robots comprises part of reasonable efforts to support the six capabilities at a minimal threshold.

5. Therefore, society ought to make reasonable efforts to ensure access to sex robots for older adults with disabilities that impair sexual functioning.

The crux of the argument is that our sexual desires are not mere desires; for many, they are fundamental to a sense of who they are as human beings. To shun people's sexual longing or behaviour, or to leave people who struggle with disabilities that impair sexual functioning to fend for themselves, conveys a lack of respect for persons.

Backing for premise 3 relies on defences of capability approaches found in the capability literature. ${ }^{30-33}$ These defences share the general idea that central human capabilities comprise a set of basic moral entitlements that societies have a duty to uphold at a threshold level. Like Nussbaum, ${ }^{30}$ I claim that a societal duty to uphold capabilities at a threshold level is dignitybased, reasoning that for beings like us, leading a dignified life requires being able to be and do the central things that human beings can do and be in a minimal way. ${ }^{31}$ Other defences, such as Anderson's, are equality-based; Anderson emphasises that 'citizens have a claim to a capability set sufficient to enable them to function as equals in society' (Anderson, p83). ${ }^{34}$

The second and fourth premises gain ground by elucidating ways in which sexuality is integral to the capacity to have a life narrative; be emotionally, mentally and physically healthy; experience bodily integrity; feel and express a range of human emotions; reflect on and choose a plan of life; and affiliate deeply with others. Let us consider how each of the six central capabilities relate to the ability to be sexual, how ageing and disability undermine them, and how sex robots can offset these deficits.

\section{Life}

The first capability captures the idea that a human life can be understood as an unfolding story, displaying a kind of unity, analogous to narrative unity. We can view the moments of our life as a meaningful whole, something that we can make sense of. When we say, metaphorically, that 'everyone has a story' we are invoking this intuitive sense of life as a narrative. Sexuality plays an integral role in the narrative of a human life and in who we perceive ourselves to be. When societies label later-life sexuality as distasteful, non-productive or pathological, this diminishes the narratives available to older people. Even long after a storyline of 'asexual older people' is discredited, it continues to function as a cultural resource people draw on or resist. For example, although gerontophilia lacks a biomedical basis and is no longer recognised, it contributes to a sexual climate of age inequality. Even after alternative scripts for old age are added to the mix, not all scripts enjoy the same status; some attain normative or dominant status and are set apart and considered culturally available, canonical and master. ${ }^{35}$ For example, in the West today, heterosexual storylines are normative, yet we do not find heteronormativity in ancient Greece. ${ }^{36}$ While problematising later-life sexuality is a relic, debunked by modern medicine, it remains a powerfully normative relic. As such, it can thwart attempts by older people to create narratives that include sexual expression.

Setting aside the detrimental effects of ageist attitudes, how can sex robots generate positive effects that enhance life narratives? 
One way this can occur is by generating counternarratives that include sex robots. Robots designed to integrate with the life narratives of older users may bear little resemblance to contemporary sex robots that dominate film and television shows, such as the young gynoids, Ave and Kyoko, of the 2014 film Ex Machina or those featured in the 1976 television series The Bionic Women and the Austin Powers film series. These images tilt towards users who are young, able-bodied, heterosexual and male. By contrast, sex robots designed for older people might resemble a deceased spouse in appearance or manner. For an older user, a desirable sex robot might evoke film stars of a bygone era, like Sidney Portier or Bette Davis.

As societies age, we can expect to see more television and filmic portrayals featuring 'old love' (long-lasting romance) and 'new love' involving older people. A recent review of films portraying long-lasting romance with at least one 'bedroom scene' found a mainstay of old love was talking and sharing, handholding, glances across a room and moments of tenderness, suggesting that sex robots will need to engage older users romantically and affectionately, as well as sexually. ${ }^{37}$ Popular television series depicting new love, such as Netflix's Grace and Frankie (2015), cast older adults falling in love and having sex in a positive light, including both gay and straight sexual encounters. As more narrative possibilities emerge in popular media, it will be easier to imagine incorporating sex robots into the narratives of older disabled people's lives.

\section{Health}

The second capability that links to sexuality is the ability to be physically, mentally and emotionally healthy. An integral component of health is sexual health, which encompasses both physical and psychological dimensions, such as being able to perform in a range of ways to express oneself sexually; derive pleasure from physical intimacy; and be able to engage in sexual activities without shame, humiliation or ridicule. The World Association for Sexual Health defines 'sexual health' as including 'identifying addressing and treating sexual concern, dysfunctions and disorders. ${ }^{38}$ The Pan American Health Organisation and WHO understand sexual health to refer broadly to the experience of the ongoing process of physical, psychological and sociocultural well-being related to sexuality...(It) is evidenced in the free and responsible expressions of sexual capabilities that foster harmonious personal and social wellness, enriching individual and social life. It is not merely the absence of dysfunction and/ or infirmity. ${ }^{39}$ Research demonstrates a positive correlation between general health and sexual partnership, frequency of sexual activity, good quality sex life, and interest in sex among middle-aged and older-aged adults. ${ }^{40}$

While sexual dysfunction impacts people of all ages, it is most prevalent among older age groups; according to one estimate, $40 \%-45 \%$ of adult women and $20 \%-30 \%$ of adult men report at least one sexual dysfunction. ${ }^{41}$ The Global Study of Sexual Attitudes and Behaviours found that among sexually active people aged $40-80$ years, $28 \%$ of men and $39 \%$ of women report at least one problem with sexual functioning during the prior year. ${ }^{42}$ Whether age-related changes or disease and disability result in older people being deprived of sexual capabilities depends on the supportive services available. With assistance, older adults can continue to be sexual in ways they value, including sustaining sexually intimate relationships, deriving pleasure from sexual activity and preserving high-quality sexual lives. Evidence indicates that older adults want resources to gain greater control and autonomous choice over their sexual lives and want to improve their ability and desire to give and receive pleasure. ${ }^{9}$ Sex robots represent one important tool to help older people with disability maintain sexual health.

However, sceptics might worry that furnishing sex robots will produce the opposite effect, diminishing sexual health by fostering dependency on technology for sexual satisfaction. One way to answer this concern is to say that preference for robotic over human sex partners is atypical, not pathological. The latest (2013) edition of DSM (DSM-5) distinguishes paraphilic 'interests' from paraphilic 'disorders', suggesting that atypicality can be present within a range of healthy sexual interests. A related reply would be to argue that digisexuals, or people whose preferred mode of sexual experience and relating is via immersive technologies (with or without a human partner), represent a new sexual orientation that should be accepted. ${ }^{43}$ Levy, for instance, predicts that prejudice against digisexuals will be overcome, just as prejudice against homosexuality, oral sex, fornication and masturbation have changed so much with time. ${ }^{44}$

\section{Bodily integrity}

The capability for bodily integrity is a form of self-determination through the body. It includes the ability to express sexual feelings and engage in sexual behaviours. Capability for bodily integrity figures prominently in the lives of older adults, with most older adults reporting being engaged in spousal or other intimate relationships and reporting that being sexual is an important source of meaning in life. ${ }^{9}$ However, sexual capability is at risk during later life due to increased risk of cognitive impairments that interfere with sexual agency; physical impairments that limit the ability to carry out sexual desires; and denigrating beliefs, such as ageist, ableist and sexist attitudes that result in older people being viewed (by themselves and others) as incapable or uninterested in being sexual. Chronic diseases, such as stroke, heart disease, cancer, diabetes and depression, are more frequent during later life and can disrupt people's ability to function sexually. Parkinson's disease, for example, frequently impairs sexual function due to reduced sexual coordination, erectile dysfunction, vaginal dryness, lack of climax, low libido and difficulties with orgasm. ${ }^{45}$ With all types of chronic disease, additional hurdles to sex can arise when one partner takes on the role of caregiver.

Losing the ability to express sexual feelings through the body deprives older people of an important source of love and meaning. To the extent that sexuality is entwined with a person's identity, the erosion of sexual capability leads to a loss of one's sense of gender identity, for example, 'being a man' or 'being a woman'. When an older person's body no longer does what they intend it to do, sex robots could intervene, enabling physical contact according to user specification. Just as service robots are being designed to assist older individuals with functions such as eating, dressing and bathing, they might be designed to assist with social functions, serving as sources of affiliation and sexual partnership.

\section{Emotions}

The fourth capability related to sexuality is the capability for emotions. Sexual acts not only express feelings, such as pleasure, but also link to emotions, enabling people to be caring, courageous, kind, generous and compassionate. ${ }^{46}$ To illustrate, consider the true-life story of Mark, described in O'Brien's 1990 essay, On Seeing A Sex Surrogate. ${ }^{47}$ The essay introduces us to Mark, a 38-year-old man with polio and severe paralysis who has lived in an iron lung since the age of 6 . Mark has had no sexual experience. Acting on advice from his therapist and priest, he decides to see a sex surrogate, a therapist who helps patients with psychological issues related to sex by using bodily 
awareness exercises and offering sexual experiences, including intercourse. Mark learns he can enjoy a fulfilling sexual life when he has a partner to be sexual with. While the essay ends with Mark unable to find a human sex partner and concluding that pursuing women is a 'seemingly doomed project', ${ }^{48}$ this conclusion is subsequently challenged. The 2013 film The Sessions follows Mark's actual life story and ends with Mark finding a loving spouse. ${ }^{49}$ Mark's real-life story reveals how crucial the sex surrogate was for Mark's sexual awakening, creating for him a possibility that did not exist previously. The case demonstrates the courage that sexual intimacy can call on when persons with disabilities struggle with impairments that make sexual activity physically, emotionally or interpersonally awkward and difficult. Like Mark, some older people suffer profound psychological and physical challenges that pose obstacles to sexual endeavours. ${ }^{50}$ For them, working with a sex robot to face and overcome challenges enacts courage and restores a sense of wholeness and meaning to life.

\section{Practical reason}

Practical reason refers to a person's ability to reflect on and choose a plan of life that expresses authentic values and ends. Sexual partnership is a centrepiece of many people's life plans, because for many, such relationships enable closeness, happiness and self-fulfilment. While not all people identify as sexual, all have reason to value the ability to be sexual. For some, loving sexual relationships make by far the most significant contribution to 'a meaningful, fulfilling, and textured human life', and some hold that a world in which no one was deeply vulnerable in such ways would be 'inhuman' (Tsai, p169-170). ${ }^{51}$ Some argue that sex can achieve a level of passion with 'no equal in other forms of interaction' and that it marks a moment of deep significance when this occurs (Thomas, p59). ${ }^{52}$ If this is correct, then supporting a person's plan of life requires supporting their ability to incorporate being sexual into their life plan.

It might be objected that by old age, people have had a fair share of what sex has to offer, and any claim to support for sexual capabilities is relatively weak. However, in reply, it is not clear why old age is designated as the turning point for having had a fair share. Other points along life's trajectory may be more obvious markers; for example, after reproduction, sex has fulfilled its biological purpose.

\section{Affiliation}

The next central capability related to sexuality is affiliation. It is sometimes held that affiliating with others is the underlying goal of erotic desires and behaviours. Aristotle, for example, held that being loved, rather than having sex, was the ultimate purpose of sexual desire. ${ }^{53}$ Similarly, Mill held that loving relationships were preferable to erotic pleasure alone and represented a higher type of pleasure. ${ }^{54}$ According to these analyses, the highest types of sexually intimate relationships give recognition and affirmation to a person in their entirety as unique and loveable. ${ }^{55}$

When older people cannot reciprocate sexually, their capability for affiliating diminishes. In such instances, sex robots can be a lifeline to human intimacy, with fewer side effects and risks than alternatives, such as medication or invasive procedures. Sex robots also play an important role as friends and companions for socially isolated people. ${ }^{56}$ More than any other age group, older adults are at risk of having no one. ${ }^{57}$ While it might initially seem far-fetched to suggest that sex robots could offer a viable substitute for humans, people already perceive and treat robots not just as machines but also as companions and partners. ${ }^{58}$ Unlike sex devices that function merely to enhance sexual pleasure, people bond to sex robots and feel close to them. Sex robots create the possibility not just of sexual pleasure but also of sexual relationships and interpersonal intimacy.

Sceptics might counter that the relationship between a person and their sex robot is unidirectional and inferior. ${ }^{59}$ Support for this claim comes from a reciprocity view of sex, such as that of Nagel's, which holds that without mutual desire, sex is a kind of perversion. ${ }^{60}$ In reply, while the mutual desire view of sexuality has much to recommend it in human-human sexual relationships, a different view is needed for human-robot sexual relationships. In the human-human case, unidirectional sex brings to mind objectionable instances where one party is made limp or ineffectual by being intoxicated, drugged or forcibly restrained. By contrast, robots are instruments by definition, and all of their functions, sexual or otherwise, are designed to serve users' ends. A more apropos way of understanding human-robot sex is the capability view, which focuses on how sex robots enable sexual capabilities. Seen in this light, sex robots are not a perversion but a way to enhance dignity by shoring up capability shortfalls.

\section{REPLIES TO CRITICS}

Critics might object to sex robots on several additional grounds.

\section{Intellectual impairment}

First, even if there is general agreement to afford access to sex robots for older adults with disabilities, it might be thought that intellectual impairment is a limiting case. When people with diminished capacity cannot appreciate fully what they are doing, they should not have access to sex robots. However, this approach fails to recognise that decisional capacity falls along a continuum, and the proper standard for capacity varies, based on the type of decision and risk. ${ }^{61}$ As Tarzia et al note, one way that providers at long-term care facilities fall into the trap of applying overzealous, informed consent protocols to sexual matters is that standard informed consent policies were originally designed for different applications, such as consenting to research or surgery. ${ }^{62}$ In these situations, a high bar for informed consent makes sense; yet, the same standard is out of place in the case of sex robots. Although people with intellectual impairment are vulnerable to sexual abuse and should be protected against it, it hardly follows that they have no right to be sexual and should be barred from the tools they need to accomplish this. Denying support for sexual capabilities creates its own risks and vulnerabilities, such as social isolation and loneliness.

A helpful way to frame practices around sex robots for older adults with intellectual impairments is to ground them ethically in Mill's harm principle, which holds that individual liberty is justifiably limited only to prevent harm to oneself or others. ${ }^{63}$ Applied to sexual activity, the harm principle entails that sexual liberties should be restricted only as necessary to protect people's health or safety. In institutional settings where third parties exercise control over access to sex by controlling privacy, visitation and rules of conduct, the harm principle puts the onus on those who wish to deprive a resident of sexual opportunities to show that it places the resident or others at undue risk. ${ }^{62}$ Erring in the other direction, on the side of risk prevention, protects the institution but runs afoul of residents' ability to lead dignified lives.

\section{Deceitful}

A further objection holds that the human-sex robot relationship is grounded on a deceitful exchange. According to Turkle, even if they make us feel good, sex robots are morally problematic; inevitably, our relationship with them rests on the false belief that an 
artefact knows and cares about us. ${ }^{64}$ Yet, in reply, it is not clear that holding false beliefs is necessary in order to enjoy relationships with sex robots. For example, a person who is sexual with a robot might enjoy and relate to it as a robot, without projecting consciousness or other human qualities onto the object. Even if it were necessary to hold false beliefs in order to find robothuman sex meaningful, truth may become a less weighty value for some older individuals compared with other values, such as having interactions with others to look forward to, plan for and think about. If a user repeatedly insists on thinking of their robot as someone who cares about them, it might be cruel to challenge this and insist on truth.

\section{Bias}

A third objection holds that sex robots reflect sexist, racist, ableist, ageist and heterosexist attitudes. Sanctioning sex robots is tantamount to endorsing these prejudiced attitudes. Thus, Gutiu expresses dismay that sex robots are overwhelmingly made to represent social stereotypes of female beauty ${ }^{65}$ In reply, rather than doing away with sex robots, a better response to bias is to give sex robots a makeover. Perhaps, increased diversity is already in the offing. For example, while the TrueCompanion's website (mentioned previously) is adorned with stereotypic images of young white women, it also offers choices of skin colours, along with a transgender penis that attaches to a removable vaginal insert. ${ }^{66}$ Imagining the possibilities, O'Neil muses that 'women could get spoiled by dashing menbots' ${ }^{67}$ van Wynsberghe recommends engaging in 'a conversation in the general public about what is acceptable, permissible and what should be promoted'. ${ }^{68}$

\section{Masturbation}

Some might object to sex robots on the ground that people with disabilities can avail themselves of other options, such as masturbation. In reply, although many people with disabilities are able to self-stimulate, part of what is sought through engaging in sexual relationships is relationships. Self-stimulation alone cannot satisfy this desire. Schlossberger holds that this is one of the reasons why people hire prostitutes, even though manual stimulation is a more effective way than intercourse to become physically aroused. ${ }^{69}$ It also explains why we do not think of masturbating as having sex but as a substitute for sex. As Danaher notes, 'if masturbation counts as having sex with yourself, anyone who masturbates thereby has homosexual sex; and perhaps incestuous sex' (Danaher, p21). ${ }^{70}$

\section{Prostitution}

A critic of sex robots, such as Richardson, might argue that sex robots are objectionable for the same reason that prostitution is, namely, they enact an extreme form of objectification. ${ }^{71}$ When robots are disproportionately made in the image of young women designed for sale to male customers, the worry is that they will reinforce the tendency to think of women as objects in the service of men. In reply, although this is a disturbing feature of current sex robots, it is not an inevitable feature. Rather than rejecting sex robots outright, we might instead broaden their appeal. In fact, a key advantage of sex robots over prostitution is that they can support sexual capabilities without directly violating the rights of any other person. While this reply is not without detractors, namely, those who ascribe rights to robots, it is a reasonable view to hold.

\section{Rape}

A final objection to sex robots is that they enact rape when users engage in sex without consent. Sparrow, for example, raises the possibility that it might be 'morally problematic' to design realistic female robots that explicitly refuse to consent to sex in order to facilitate a rape fantasy (Sparrow, p2). ${ }^{72}$ However, in reply, it is only morally wrong to the robot if the robot is a sentient being, which robots (so far) are not. The notion of 'consent' packs in the false assumption that the robot is making a willful choice, which is overridden. Part of making the fantasy 'come alive' for the user is that it is a good simulation, one that allows the user to project the subjective status of 'not consenting' onto the robot and feel as if they are raping someone. Yet, in reality, a robot's consent (or lack thereof) is automated; that is, the robot executes an algorithm or carries out a programme.

Sparrow maintains that even if raping a robot is fake rape, it is wrong because it represents harmful behaviour when robots look sufficiently like a real person. ${ }^{72}$ Sparrow reasons that sex without explicit consent is wrong when what it represents for the agent is having sex with a person; the only way to avoid the wrong is to design robots that are clear imposters. However, while someone might find a realistic-looking robot offensive, if these objects are used behind closed doors, whose business is it? In truth, someone with a vivid imagination can close their eyes and conjure up whatever image they want, including a reallive person, and project that person onto an object or another person they are having sex with. Doing so is a sexual fantasy and a source of real sexual excitement when a person 'gets caught up in it'. Sexual fantasising is a common healthy component of sexual life, and engaging in it harms no one.

Yet Danaher disputes this conclusion, arguing that someone is harmed when a person imagines raping a sex robot, namely, the user. The point is that forcing oneself on a sex robot leads to developing a viscous character. Yet, an alternative plausible interpretation is that the disposition cultivated is a disposition to use sex toys; it is contestable whether that disposition is morally repugnant. Sparrow himself acknowledges that no one is actually having sex or being raped when a (non-sentient) sex robot is involved, because 'strictly speaking, sex with robots is actually masturbation with robots' (Sparrow, p4). ${ }^{72}$ However, a more accurate telling would be to say that a sex robot is a sophisticated sex toy, rather than a form of masturbation, since robots, like sex toys can be used by couples. For instance, if one member of a couple had a fantasy to enact a ménage à trois, the robot could play a third person. If what we call 'sex with robots' is more accurately sex with toys, worries about rape are out of place and might be offensive. Specifically, the suggestion that robots can be raped or that this could be wrong might be deemed offensive by people who have been raped. Drawing such a comparison belittles the violation they experienced, suggesting that it was no worse than what might happen to a sex robot.

\section{CONCLUSION}

Older people suffer disproportionately from disabilities that interfere with their sexual capabilities. When this occurs, they often do not receive the support they need to maintain sexual function. Not only do older adults face ageism and ableism in the communities in which they live but also healthcare professionals typically do not broach the subject of sexuality, and medicine is peppered with examples of ageist beliefs about later-life sexuality. This paper has shown that the non-voluntary absence of sex from someone's life is not just a bad thing but also a threat to a person's identity and dignity.

Acknowledgements An early draft of this paper was presented at the June 2019 international workshop, "Social Impacts of Sex Robots and the Future of Human 
Relations," held at City University of Hong Kong, Kowloon, Hong Kong. I am grateful to conference participants for valuable feedback, especially Xie Wenye, Mark Cherry, and Fan Ruiping. I also wish to thank Nina Begus and 2 anonymous reviewers of the journal for helpful comments on an earlier version of the paper.

Funding The authors have not declared a specific grant for this research from any funding agency in the public, commercial or not-for-profit sectors.

Competing interests None declared.

Patient consent for publication Not required.

Provenance and peer review Not commissioned; externally peer reviewed.

Data availability statement There are no data in this work.

ORCID iD

Nancy S Jecker http://orcid.org/0000-0002-5642-748X

\section{REFERENCES}

1 Lindau ST, Schumm LP, Laumann EO, et al. A study of sexuality and health among older adults in the United States. N Engl J Med Overseas Ed 2007;357(8):762-74.

2 Lindau ST, Dale W, Feldmeth G, et al. Sexuality and cognitive status. Journal of the American Geriatrics Society 2018;66:1902-10.

3 Lindau ST, Schumm LP, Laumann EO, et al. A study of sexuality and health among older adults in the United States. N Engl J Med 2007;357(8):762-74.

4 Officer A, Fuente-Núñez dela, V. A global campaign to combat Ageism. Bull World Health Organ 2019;96:299-300.

5 Simpson P, Horne M, Brown LJ, et al. Older care home residents, intimacy and sexuality. Ageing and Society 2015.

6 Walz T. Crones, dirty old men, sexy seniors. Journal of Aging and Identity 2002;7(2):99-112.

7 Mahieu L, Anckaert L, Gastmans C. Intimacy and sexuality in institutionalized dementia care. Health Care Analysis 2014:1-20.

8 Taylor A, Gosney MA. Sexuality in older age: essential considerations for healthcare professionals. Age and Ageing 2011;40(5):538-43.

9 Lindau ST, Schumm LP, Laumann EO, et al. A study of Sexuality and health among older adults in the United States. N Engl J Med 2007;357(8):762-74.

10 Gersen JS. Sex Lex machina. Columbia Law Review 2019.;119(7):1793-810.

11 National Institute on Aging. AgePage: sexuality in later life. Available: <https://order. nia.nih.gov/sites/default/files/2018-01/sexuality-in-later-life_0.pdf> [Accessed 26 Aug 2020].

12 Shifren JL, Hanfling S. Sexuality in midlife and beyond. Harvard Health Publishing 2019.

13 Oliver D, Foot C, Humphries R. Making our health and care systems fit for an ageing population. The Kings Fund 2014.

14 World Health Organization. Defining sexual health 2002.

15 Bogaert AF. Asexuality. Journal of Sex Research 2015;52(4):362-79.

16 Krafft-Ebig RV. Psychopathia Sexualis. 12th edn. Rebman FJ: Rebman Company, 1903: 55-61.

17 Oxford English Dictionary (OED). Oxford English dictionary. Oxford university press, 2018

18 Krafft-Ebing RV. Psychopathia Sexualis. 12th edn. Rebman FJ: Rebman Company, 1903: 55-61. <https://ia800900.us.archive.org/13/items/psychopathiasexu00kr afuoft/psychopathiasexu00krafuoft.pdf>

19 Jones E. Papers on Psycho-anal. In: Oxford English dictionary (OED. 2nd edn. Oxford University Press, 2018.

20 Balon R. Paraphilic Disorders. In: Diagnostic and Statistical Manual of Mental Disorders. 5th edn. American Psychiatric Association, 2019.

21 Janssen DF. Gerontophilia. Sexual Offender Treatment(1), 2014. Available: http:/l www.sexual-offender-treatment.org/130.html [Accessed 26 Aug 2020].

22 Bering J. Perv: the sexual deviant in all of US. Scientific America 2013.

23 Money J. Paraphilias: phenomenology and classification. Am J Psychother 1984;38(2):164-79.

24 Monfort J-C, Villemur V, Lezy A-M, et al. From paedophilia to gerontophilia. Lancet 2011;377(9762):300.

25 Robot Companion. Ultimate Al talking sex robot companion. Available: <https:// www.robotcompanion.ai> [Accessed 16 May 2020].

26 McArthur N. The Case for Sexbots. In: Danaher J, McArthur N, eds. Robot sex. MIT Press, 2017: 31-45.

27 Levy D. Love and sex with robots. Harper Collins 2007.

28 Hauskeller M, Danaher J, McArthur N. Robot sex. MIT Press, 2017.: 203-18.

29 Hauskeller M. Mythologies of Transhumanism. Palgrave MacMillan 2016.

30 Nussbaum MC. Creating capabilities. Harvard University Press, 2011.

31 Jecker NS. Ending midlife bias. Oxford University Press, 2020.

32 Ruger JP. Health and social justice, reprint edition. Oxford University Press, 2009.
33 Brighouse H, Robeyns I. Measuring Justice. In: Brighouse H, Robeyns I, eds. Justifying the capabilities approach to justice. Cambridge University Press, 2010:: 80-100.

34 Anderson E. Measuring Justice. In: Brighouse H, Robeyns I, eds. Justifying the capabilities approach to justice. Cambridge University Press, 2010: 80-100.

35 Jones RL. "That's very rude, I shouldn't be telling you that": Older women talking about sex. Narrative Inquiry 2002;12(1):121-43.

36 Benedict R. Anthropology and the abnormal. J Gen Psychol 1934;10(1):59-82.

37 Doll G. Bedroom scenes. Gerontologist 2017;57(1):145-6.

38 World Association for Sexual Health. Sexual Health for the Millennium. World Association for Sexual Health, 2008.

39 Pan American Health Organization and World Health Organization (WHO). Promotion of sexual health and recommendations for action, 2000. Available: <http://www1. paho.org/hq/dmdocuments/2008/PromotionSexualHealth.pdf> [Accessed 8 Aug 2020].

40 Lindau ST, Gavrilova N. Sex, health, and years of sexually active life gained due to good health. British Medical Journal 2010;340(7746):580-91.

41 Lewis RW, Fugl-Meyer KS, Bosch R, et al. Epidemiology/risk factors of sexual dysfunction. J Sex Med 2004;1:35-9.

42 Nicolosi A, Laumann EO, Glasser DB, et al. Sexual behavior and sexual dysfunctions after age 40. Urology 2004:64:991-7.

43 McArthur N, Twist MLC. The rise of Digisexuality. Sexual and Relationship Therapy 2017;32(3/4):334-44.

44 Levy D. Love and Sex with Robots. Harper Collins e-books, 2017.

45 American Parkinson Disease Association (no date). Parkinson's and Sex. Available: $<$ https://www.apdaparkinson.org/what-is-parkinsons/symptoms/sexual-effects/> [Accessed 26 Aug 2020].

46 Halwani R. Sex and Sexuality. In: Zalta EN, ed. Stanford encyclopedia of philosophy, 2020. <https://plato.stanford.edu/archives/spr2020/entries/sex-sexuality/>

47 O'Brien M. On seeing a sex surrogate, 1990. The Sun. Available: <thesunmagazine. org/issues/174/on_seeing_a_sex_surrogate> [Accessed 26 Aug 2020].

48 O'Brien M. On seeing a sex surrogate, 1990. The Sun. Available: <thesunmagazine. org/issues/174/on_seeing_a_sex_surrogate $>$ [Accessed 7 Oct 2020].

49 Lewin B. The sessions. Fox Searchlight Pictures 2012.

50 National Institute on aging. AgePage: sexuality in later life. Available: <https://order. nia.nih.gov/sites/default/files/2018-01/sexuality-in-later-life_0.pdf> [Accessed 26 Aug 2020].

51 Tsai G. Vulnerability in intimate relationships. South J Philos 2016;54:166-82.

52 Thomas LM. The Good Society and Sexual Orientation. In: Thomas LM, Levin ME, eds. Sexual Orientation \& Human Rights. Rowman \& Littlefield, 1999: 1-78.

53 Aristotle, 350 B.C.E. Nicomachean Ethics. In: Ross WD, ed. transl., 1999, The Nicomachean Ethics of Aristotle, Batoche Books, Kitchener.

54 Mill JS. Utilitarianism. In: Reprinted from Fraser's Magazine. Longmans, Green, Reader and Dyer, 1871.

55 Brinck I, Balkenius C. Mutual recognition in Human-Robot interaction. Philosophy and Technology 2020;33:53-70.

56 Jecker NS. You've got a Friend in me: sociable robots for older adults in an age of global pandemics. Ethics Inf Technol 2020:1-9.

57 National Academies of Sciences, Engineering and Medicine, 2020. Social isolation and loneliness in older adults. National Academies Press.

58 Libin AV, Libin E. Person-Robot Interactions from the Robopsychologist's Point of View. Proceedings of the IEEE 2004;92(11):1789-803.

59 Elder A. Robot Friends for Autistic Children. In: Lin P, Abney K, Jenkins R, eds. Robot ethics 2.0. New York: Oxford Scholarship, 2017.

60 Nagel T. Sexual Perversion. J Philos 1969;66(1):5-17.

61 Buchanan AE, Brock DW. Deciding for Others. Cambridge University Press, 1989.

62 Tarzia L, Fetherstonhaugh D, Bauer M. Dementia, sexuality and consent in residential aged care facilities. J Med Ethics 2012:38(10):609-13.

63 Mill JS. On Liberty. In: Casey K, ed. On liberty. Dover Publications, Inc, 2002.

64 Turkle S. A nascent robotics culture. AAAI Technical Report Series, 2006.

65 Gutiu SM. The Roboticization of Consent.. In: Calo R, Froomkin M, Kerr I, eds. Robot law. Edward Elgar Publishing Limited, 2018.

66 Robot companion. ultimate Al talking sex robot companion. Available: <https://www robotcompanion.ai> [Accessed 16 Jun 2020].

67 O'Neil C. Maybe Sex Robots Will Make Men, Not Women, Obsolete. Bloomberg Opinion, 2018. Available: <https://www.bloomberg.com/opinion/articles/2018-01-04/ maybe-sex-robots-will-make-men-not-women-obsolete> [Accessed 26 Aug 2020].

68 van Wynsberghe A. Quoted in Knapton S Sex Robots on the Way for Elderly and Lonely.But Pleasure-Bots Have a Dark Side, Warn Experts. The Telegraph, 2017. Available: https://www.telegraph.co.uk/science/2017/07/04/sex-robots-way-elderlylonelybut-pleasure-bots-have-dark-side/ > [Accessed 26 Aug 2020].

69 Schlossberger E. Moral Responsibility and Persons. Temple University Press, 1992.

70 Danaher J. Robot sex. MIT Press, 2017.

71 Richardson K. The asymmetrical 'relationship'. SIGCAS Comput. Soc. 2016;45(3):290-3

72 Sparrow R. Robots, rape, and representation. Int J Soc Robot 2017;9(4):465-77. 